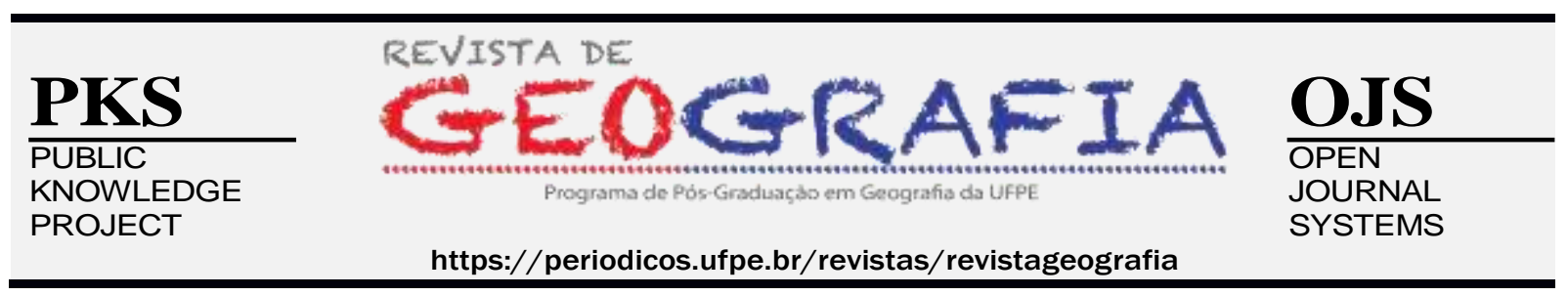

\title{
A MOBILIDADE TURÍSTICA NO CICLOTURISMO DE PONTA GROSSA, PARANÁ
}

\author{
Ana Cristina Costa Siqueira ${ }^{1}$, Carla Adriana Berdnachuk², Edson Belo Clemente de Souza ${ }^{3}$
}

${ }^{1}$ Universidade Estadual de Ponta Grossa. E-mail: anacostasiqueira@gmail.com

${ }^{2}$ Universidade Estadual de Ponta Grossa.E-mail cberdnachuk@gmail.com

${ }^{3}$ Universidade Estadual de Ponta Grossa.E-mail: ebelo2003@yahoo.com.br

Artigo recebido em 21/01/2020 e aceito em 28/07/2020

\begin{abstract}
RESUMO:
O uso de bicicletas passa a ser uma alternativa menos dispendiosa e sustentável para o meio ambiente. Para o turismo torna-se uma alternativa para apreciar a natureza de maneira sustentável e pode ser considerado como uma nova forma de fazer o turismo acontecer. O presente estudo é parte da dissertação da autora principal que consiste na análise do cicloturismo no município de Ponta Grossa ligando a cidade ao interior nos seus principais atrativos turísticos. Para realizar a pesquisa, estabeleceu-se como recorte espacial o município de Ponta Grossa nos seus espaços urbano e rural, já para a coleta de dados foi utilizado aplicação de questionário semiestruturado com os ciclistas de Ponta Grossa, disponibilizado através de link em redes sociais como o Facebook e o Whatsaap, utilizando-se como ferramenta a plataforma do Google Form, além de estudos bibliográficos. Tem-se dessa maneira, que a mobilidade torna-se imprescindível para o desenvolvimento do cicloturismo, pois a mesma atividade depende de um bom planejamento urbano e infraestrutura adequada para que possam os turistas (individuais ou em grupos) praticar essa atividade de forma segura, sem contratempos e que desfrutem dos atrativos que o município tem a oferecer de maneira proveitosa durante o passeio realizado.
\end{abstract}

Palavras chave: Mobilidade; Cicloturismo; Cidades.

\section{TOURIST MOBILITY IN CYCLOTURISM IN PONTA GROSSA, PARANÁ}

\begin{abstract}
The use of bicycles, becomes a less expensive and sustainable alternative for the environment. For tourism it becomes an alternative to enjoy nature in a sustainable way and can be considered as a new way to make tourism happen. The present study is part of the main author's dissertation, which consists of the analysis of bicycle tourism in the municipality of Ponta Grossa linking the city to the interior in its main tourist attractions. To carry out the research, the municipality of Ponta Grossa in its urban and rural spaces was established as a spatial section, while for data collection a semi-structured questionnaire was used with the cyclists in Ponta Grossa, made available through a link on social networks such as Facebook and Whatsaap, using the Google Form platform as a tool, in addition to bibliographic studies. In this way, mobility becomes essential for the development of cycling tourism, as the same activity depends on good urban planning and adequate infrastructure so that tourists (individually or in groups) can practice this activity safely, without setbacks and who enjoy the attractions that the municipality has to offer in a profitable way during the tour.
\end{abstract}

Keywords: Mobility; Cycling tourism; Cities. 


\section{INTRODUÇÃO}

Mobilidade sustentável tem se tornado, recentemente, tema de diversos debates no que se referem à busca por cidades sustentáveis. Grandes centros urbanos tendo suas estatísticas populacionadas infladas pelo aumento populacional e com isso problemas que passaram a se tornar recorrentes relacionados ao excesso de lixo, poluição e excesso de automóveis nas ruas piorando a qualidade de vida das pessoas. O padrão de mobilidade atual está sendo, lentamente, transformado. Numa perspectiva de que as cidades se tornem sustentáveis.

Em se falando de alternativas sustentáveis de transporte nos grandes centros urbanos, também, se fala sobre o uso de transportes sustentáves no turismo. Cada vez mais as pessoas estão buscando um contato maior com a natureza e melhorando as relações interpessoais através dos transportes alternativos ao carro ou ônibus por exemplo. Está ligado mais intensamente ao turismo rural, já que permite a prática de exercícios físicos, realização de trilhas e apreciação da natureza local.

No município de Ponta Grossa, projetos dão conta de construir quilômetros de ciclovias ligando a cidade aos principais pontos turísticos na zona rural. A infraestrutura cicloviária que será implantada não trará somente benficios ao turismo, mas também aos moradores locais.

Para se realizar o presente estudo, estabeleceu-se como recorte espacial o município de Ponta Grossa nos seus espaços urbano e rural. para coleta de dados foi utilizado aplicação de questionário semiestruturado com os ciclistas de Ponta Grossa, disponibilizado através de link em redes sociais como o Facebook e o Whatsaap, utilizando-se como ferramenta a plataforma do Google Form.

O cicloturismo, atividade que depende do uso da bicicleta como principal meio de transporte, está sendo implantado no mucicipio aos poucos mas sabe-se que para que maiores transformações aconteçam deve haver uma interação entre diferentes agentes (poder público, privado, sociedade local etc) para que ofereçam condições para que a atividade em si consiga ser realizada.

\section{CICLOTURISMO E MOBILIDADE}

A utilização de transportes não motorizados, como por exemplo o uso de bicicletas passa a ser uma alternativa menos dispendiosa e sustentável para o meio ambiente. No entanto, se torna menos confortável como também em algumas cidades esse transporte passa a ser menos utilizado devido a formação e o planejamento urbano que a mesma oferece, impossibilitando seu uso em alguns casos. 
Conforme Campos, Santos e Alves (2016) a mobilidade sustentável torna-se crucial para o desenvolvimento urbano, mas que devem estar associados a elementos como a qualidade de vida, a preocupação com as gerações futuras, o meio ambiente e com valorização dos espaços públicos. Nesse contexto, os autores ainda enfatizam que o debate em relação ao papel da utilização da bicicleta no campo dos transportes e do sistema viário como um todo torna-se uma preocupação, visto que poderia contribuir com a qualidade de vida dos moradores e também com a melhoria da imagem da cidade.

Para Duarte (2013) o uso da bicicleta como meio de transporte, ainda não está incluído no cotidiano dos brasileiros. Uma vez que o perfil do grupo que utiliza esse meio de locomoção é na maioria pessoas que possuem pouca condição financeira ou esportistas que a utilizam somente com a finalidade de lazer. Neste aspecto, o autor explica que este cenário é um fator, proveniente da criação da cultura do automóvel e também da falta de infraestrutura para atender os cidadãos. Por isso, Arruda (2017, p.14) menciona:

\footnotetext{
Por exemplo, são raras as cidades que dispõem de um sistema de ciclovias tão conectado quanto o sistema viário para automóveis Em geral, as vias para bicicletas são concentradas em determinadas áreas da cidade sem uma ligação formal entre elas. Esses sistemas fragmentados constituem um sério impedimento para o uso de bicicletas nas cidades.
}

Para o turismo no entanto, torna-se uma alternativa para aqueles usuários que gostam de apreciar a natureza de maneira sustentável. O cicloturismo constitui-se de uma atividade que depende do uso da bicicleta como principal meio de transporte, para tanto necessita de meios que ofereçam condições para que a atividade em si consiga se concretizar.

A sustentabilidade das cidades também necessita de uma infraestrutura adequada que atenda às necessidades dos ciclistas e cicloturistas. Para isso, deverá vir acompanhada de investimento de ciclovias, ampliação dos modais de transporte, diminuição de congestionamento e da poluição do ar, além da melhoria da qualidade de serviços de transporte público para toda a comunidade (CAMPOS, SANTOS E ALVES, 2016).

Segundo Grimm e Rodrigues (2018) o cicloturismo é uma nova forma de turismo que está relacionada ao desenvolvimento do turismo de forma responsável e que oferece experiências vinculadas a natureza, ao bem-estar físico e psicológico e ainda a própria convivência social. Neste aspecto, Saldanha, Santos e Fraga (2015) afirmam, que o cicloturismo é uma forma de motivar o habito de utilizar a bicicleta no dia-a-dia. Mas também deve-se frisar que inserção da bicicleta na rotina do indivíduo, está também relacionada a ações recreativas para fins de lazer. 
Campos, Santos e Alves (2016) reconhece que o cicloturismo também está relacionado a prática de outros segmentos turísticos, como o turismo rural, ecoturismo, turismo aventura, turismo cultural e gastronômico. De acordo com os autores, o cicloturismo torna-se de importância para o desenvolvimento do turismo responsável, e cujo sistema está sendo adotado por vários países do mundo, que consideram a bicicleta como um meio de transporte do futuro devido ser um meio de transporte que não polui a natureza, já que torna-se adequado para a inclusão do turista com relação a locomoção, passeios receptivos e "city tours".

Dessa maneira, a mobilidade torna-se imprescindível para o desenvolvimento do cicloturismo, pois essa atividade depende que haja uma infraestrutura, bem como planejamento urbano que também atenda às necessidades dos cicloturistas, para que possam praticar a essa atividade de forma segura, sem contratempos e que desfrutem dos atrativos de maneira proveitosa durante o passeio realizado. Assim, é necessário mencionar o município de Ponta Grossa-PR que dispõe de diversos atrativos turísticos, mas que também necessita de meios e planejamento para que a atividade consiga desenvolver-se de maneira positiva e possa trazer benefícios para todos os moradores e seus visitantes.

\section{SITUAÇÃO DO CICLOTURISMO EM PONTA GROSSA, PARANÁ}

A parceria da Fundação Municipal de Turismo - FUMTUR com o Instituto de Pesquisa e Planejamento Urbano de Ponta Grossa - IPLAN visa desenvolver o projeto voltado para incentivar a prática do cicloturismo no município.

O projeto referente à construção de ciclovias foi entregue ao prefeito em 27 de novembro de 2017. O objetivo principal é ligar o bairro de Uvaranas (espaço urbano) com o distrito de Itaiacoca (espaço rural). Essa ciclovia terá, aproximadamente, 14 quilômetros, sendo que o investimento para a obra chega a quase $\mathrm{R} \$ 3,2$ milhões. A pista terá início na rotatória que se encontra em frente ao Campus de Uvaranas, da Universidade Estadual de Ponta Grossa - UEPG, seguindo em direção à rodovia até o vilarejo do Passo do Pupo e início da via que segue para o Biscaia. A escolha desse traçado se deve ao fato de já ser usual para ciclistas de Ponta Grossa, sendo também umas das rotas que integram o Cicloturismo, porém a atual ausência de iluminação e de estrutura, além de acostamentos inadequados, torna a via perigosa para os praticantes da atividade (PREFEITURA MUNICIPAL DE PONTA GROSSA, 2017).

Quanto a isso, a Prefeitura Municipal de Ponta Grossa (2017) haverá a inserção de ciclo faixas, novos investimentos nesse segmento principalmente para o desenvolvimento do Cicloturismo Urbano e o Cicloturismo Rural. 
Através da perspectiva de melhoria com a implantação das ciclovias, os atrativos de Ponta Grossa, principalmente os que se encontram no espaço rural, poderão ser contemplados pelos praticantes do cicloturismo. Porém, as ciclovias são apenas um elemento que compõem o cicloturismo, pois a implantação dessa atividade exige muito mais, como exemplo deve-se mencionar a infraestrutura cicloviária, divulgação dos atrativos, acesso, segurança e sinalização. A par disso, a atividade também se torna uma forma de estimular o uso da bicicleta como transporte e também promove a circulação de pessoas, já que se poderá ter mobilidade, sendo a mobilidade turística e a mobilidade rural e urbana contempladas nesse processo.

Assim, pode-se dizer que os projetos de Ponta Grossa são fundamentais para que haja a melhoria da mobilidade turística no município, seja para oferecer melhores condições aos visitantes para os atrativos turísticos existentes, seja para abrir e incluir novas opções. Os lugares que já funcionam com turismo e os outros com potencial, todos são lugares com paisagens diferenciadas e únicas, por isso necessitam de uma infraestrutura que possua qualidade na mobilidade e no atendimento, o que exige a união de todos os agentes sociais.

\section{VISÃO SOBRE A MOBILIDADE TURÍSTICA A PARTIR DA PERSPECTIVA DO TURISTA-CIDADÃO}

Tratemos agora do conceito de Gastal e Moesch (2007) quanto ao turista-cidadão. Referem-se eles aos residentes de um município ou de uma cidade como consumidores dos espaços turísticos. Nessa perspectiva, pode-se então igualar os residentes de Ponta Grossa como turistas-cidadãos, pois, ao se deslocarem para os lugares turísticos, também consomem o espaço mediante, por exemplo, aquisição de souvenires, obtenção de fotografias e até mesmo consumo da gastronomia local.

E o pensamento de Carlos (2005), que afirma que o lazer, tal qual o turismo, é uma forma de mercadoria, pois as mercadorias estão contidas no universo do consumo do espaço, devido à união do tempo de trabalho com o tempo de não-trabalho, que ligam-se para a mercantilização dos espaços em busca do lucro. Alguns lugares, como os atrativos de Ponta Grossa, tornam-se concretos a partir do consumo que o turismo enquanto mercadoria propicia.

Então, a partir disso os ciclistas, serão entendidos como turistas-cidadãos, pois, conforme foi dito, também consomem os atrativos turísticos e os equipamentos de Ponta Grossa. Por isso as suas opiniões a respeito da mobilidade turística são de relevância nesse estudo e são parte dos agentes sociais. 


\section{METODOLOGIA}

Para a realização do presente estudo, estabeleceu-se como recorte espacial o município de Ponta Grossa para este estudo de caso que abrangeria os espaços urbano e rural do município de Ponta Grossa onde se localizam os seguintes atrativos turísticos: Abadia da Ressurreição, Adega Porto Brazos, Museu dos Campos Gerais, Museu de Arqueologia e Parque Estadual de Vila Velha, contidos no espaço urbano e rural do município de Ponta Grossa, estado do Paraná no Brasil, caracterizando o recorte territorial. A escolha dos atrativos turísticos se deu por meio das categorias do método geográfico como a forma, a função, estrutura e processo, conceito utilizado por Santos (1997). Os atrativos mencionados possuem uma forma bem como funções turísticas diferenciadas, assim como, dependem de um estrutura interna e externa e todos passaram pelo processo de turistificação agregando a função turística as suas antigas funções. E, como recorte temporal, optou-se pelos atrativos atuantes na atualidade.

A pesquisa também contou com aplicação de questionário semiestruturado com os ciclistas de Ponta Grossa, disponibilizado através de link em redes sociais como o Facebook e o Whatsaap, utilizando-se como ferramenta a plataforma do Google Forms, que obteve-se 38 respostas de ciclistas residentes de Ponta Grossa, mas que também fazem cicloturismo. O questionário foi baseado no documento organizado pelo Transporte Ativo (2018), que ficou disponível de 20 a 29 de outubro de 2018, até cessarem as respostas. Devido à dificuldade da pesquisadora principal de encontrar pessoalmente esse tipo de público para a aplicação do questionário, optou-se por esse recurso, visto que também os usuários desse meio de transporte conseguiram expor suas opiniões de maneira espontânea.

\section{OPINIÃO DOS CICLISTAS DE PONTA GROSSA-PR}

Os cicloturistas e também moradores do município Ponta Grossa. A eles se aplicou questionário semiestruturado no período de 20 a 29 de outubro de 2018, o que foi realizado via ambiente virtual do Facebook e WhatsApp. Eles também se enquadram no conceito de turistacidadão, pois, realizam visitações aos atrativos do seu próprio município de residência a fim de conhecer melhor esses lugares. Então foi obtida a participação de 38 ciclistas, dentro dos quais $34 \%$ identificaram como do sexo feminino e $66 \%$, do sexo masculino.

Quanto à faixa etária dos entrevistados, a maioria deles (37\%) se declarou pertencer à faixa de 19 a 25 anos. Depois $24 \%$ deles se enquadraram na faixa dos 32 a 41 anos; $18 \%$, de 42 a 51 anos; $13 \%$, de 26 a 31 anos; $5 \%$ de 52 a 61 anos e 3\%, menores de 18 anos. A escolaridade predominante dos respondestes, conforme a declaração de $63 \%$ deles, é a de ensino superior 
completo, seguida de $19 \%$ ainda cursando o ensino superior. Quanto aos demais, $16 \%$ deles possuem ensino médio completo e $2 \%$ ainda cursavam o ensino médio.

Para se conhecer a respeito do uso da bicicleta por parte dos entrevistados, a maioria dos respondentes (42\%) afirmou que utilizam bicicleta uma vez por semana, $26 \%$ mencionaram o uso duas vezes por semana; $16 \%$ utilizam até três dias na semana e outros $16 \%$, mais de 3 dias.

Ainda a respeito do tempo do uso da bicicleta, também se questionou sobre há quantos anos utilizam bicicleta como meio de transporte. Quanto a isso, a maioria dos entrevistados (34\%) informou que faz 5 anos ou mais; 24\% deles informaram que pedalam já de 2 a 3 anos; $13 \%$, de 3 a 4 anos; $11 \%$, de 6 meses a 1 ano e 5\%, menos de 6 meses. Outros $13 \%$ não souberam responder. O tempo de uso da bicicleta se torna necessário pelo fato de permitir conhecer se esse público é usuário habitual da bicicleta ou não, para que possamos tirar as conclusões a respeito da mobilidade e, por fim, a mobilidade do turismo em Ponta Grossa.

A partir dos dados quanto ao tempo de uso da bicicleta, pode-se perceber que a maioria dos entrevistados tem a bicicleta como uso habitual, porém não utiliza todos os dias da semana para a realização de deslocamentos diários, e sim em dias específicos da semana. Assim se torna necessário também apresentar a principal motivação para o uso da bicicleta (Gráfico 1).

Gráfico 1 - Motivo para uso da bicicleta

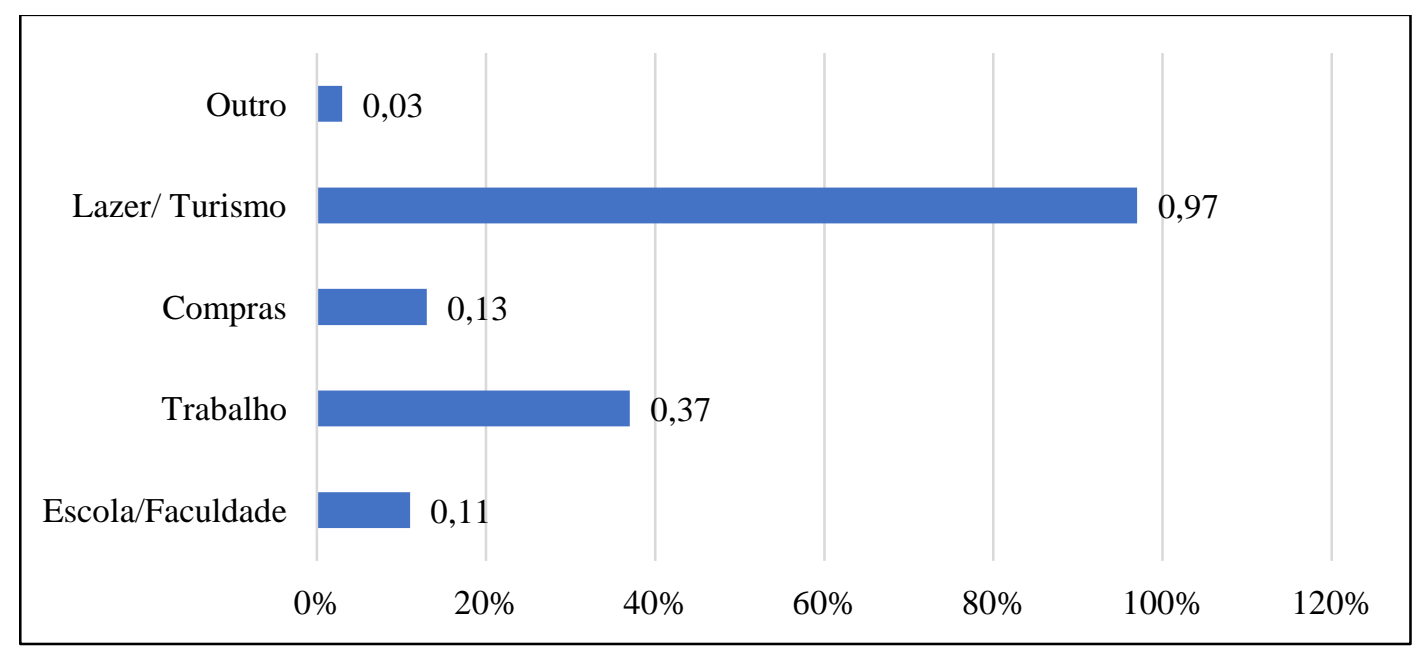

Fonte: Dados obtidos pela autora nas respostas ao questionário aplicado em outubro de 2018

A atividade com bicicleta que mais foi mencionada foi a de lazer/ turismo e, por segundo, a de trabalho, seguida de uso relacionado a compras. A partir desses dados, pode-se então compreender que a principal atividade realizada pelos entrevistados é o turismo. Isso 
indica a necessidade de uma infraestrutura adequada para a prática da atividade em Ponta Grossa. Há que compreender que, embora não sejam pessoas que morem fora, senão em Ponta Grossa mesmo, também frequentam os mesmos espaços que os cicloturistas percorrem com suas bicicletas e consomem os mesmos espaços, tornando-os turistas-cidadãos.

A infraestrutura cicloviária deve ser implantada não somente com a finalidade turística, mas também com o objetivo de se atender aos seus moradores locais. Ocorre, porém, que, para atender a todos os cicloturistas são necessários outros elementos que também fazem parte dessa infraestrutura, como a sinalização, estacionamento para bicicletas e divulgação.

Quanto à infraestrutura, no Gráfico 2 aparecem muitas reclamações quanto à falta dessa infraestrutura e também falta de segurança pública aos ciclistas de Ponta Grossa. Cabe declarar que a mobilidade turística necessita desses elementos para que bem se possam normalizar essas vias de deslocamento. Um esquema de segurança deve estar implantado, pois a bicicleta é um meio de transporte que torna o seu usuário mais vulnerável a acidentes, em especial onde há infraestrutura deficiente, sem mencionar eventuais desrespeitos por parte de motoristas de veículos motorizados.

Gráfico 2 - Problemas que o entrevistado já enfrentou no uso da bicicleta como meio de transporte em Ponta Grossa/PR

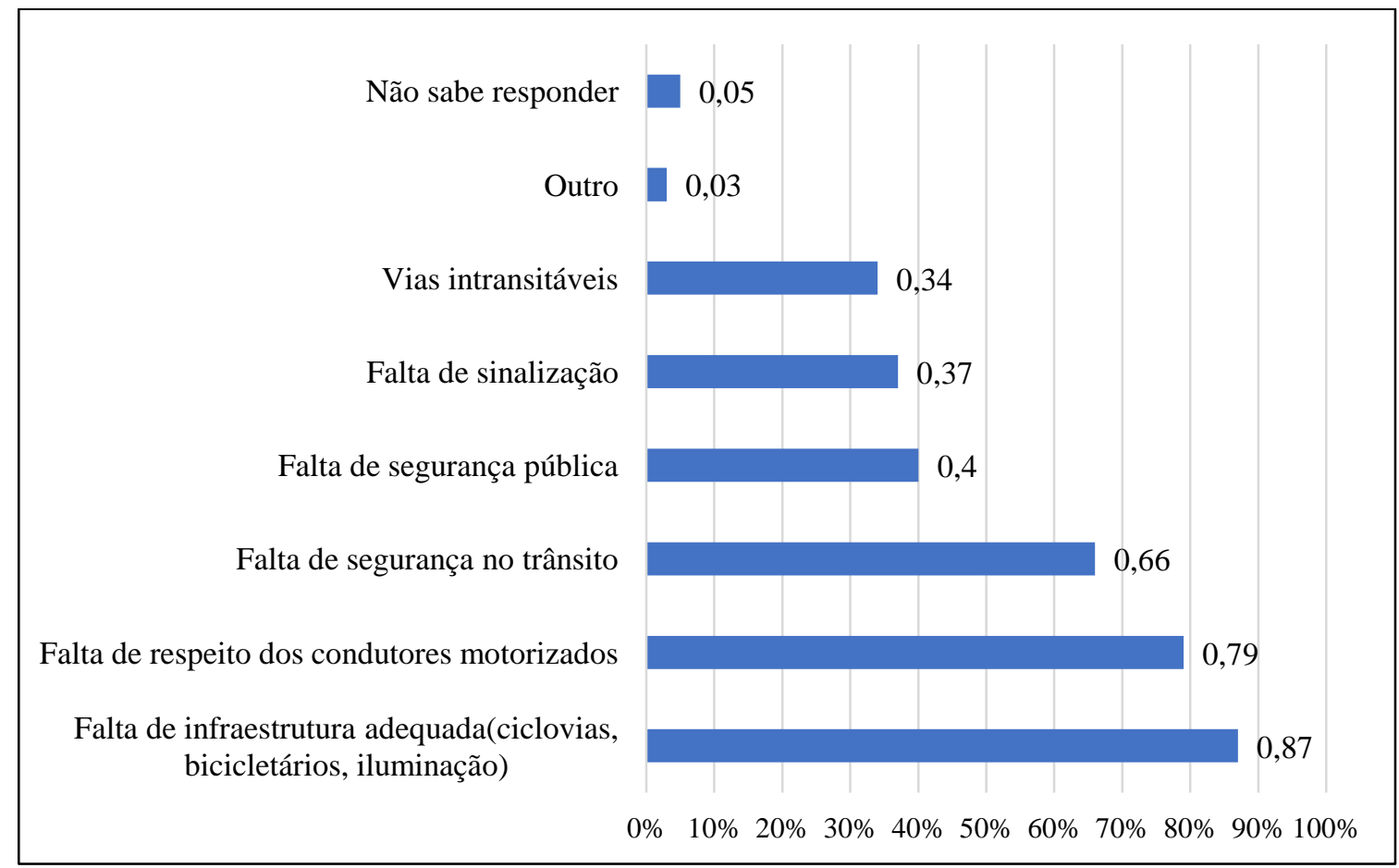

Fonte: Dados obtidos pela autora nas respostas ao questionário aplicado em outubro de 2018. 
A melhoria desses aspectos poderia trazer mais incentivo para que os moradores utilizassem mais esse tipo de veículos, uma vez que pode trazer mais benefícios à população como uma alternativa de transporte mais saudável, além de ajudar na redução de veículos motorizados. A par disso, cabe comentar que a utilização de veículos não motorizados, como a bicicleta, não oferece a rapidez de viagem que um veículo motorizado oferece, mas, para o turismo poderia tornar-se uma alternativa de passeios mais atraentes e também, por isso, necessitaria de uma infraestrutura diferenciada e que não é encontrada na maioria dos atrativos do município.

Almeida, Giacomini e Bortoluzzi (2013) afirmam, que há certo preconceito envolvendo indivíduos que utilizam o transporte motorizado e mudar para veículos não motorizados como as bicicletas. Outras questões também dificultam como o planejamento urbano da cidade. Assim, pode ser que as distâncias a percorrer sejam maiores, o que dificulta o deslocamento por bicicleta, ou pode ocorrer de a adequação da estrutura viária, por várias razões, seja muito complicada, envolvendo investimentos altos demais para a cidade.

Por essas razões, esse público foi questionado em relação ao deslocamento até os atrativos que fazem parte do recorte territorial estabelecido (Gráfico 3), sendo que, como resposta, a maioria indicou que se desloca apenas no entorno do Mosteiro da Ressurreição. Nesse aspecto, afirma-se que os ciclistas de Ponta Grossa costumam frequentar esses espaços turísticos. Desse modo, ressalta-se a importância de implantar uma infraestrutura no roteiro principal, bem como acessos para que a mobilidade fique facilitada e, a partir disso, todos os perfis de ciclistas consigam ser bem atendidos. 
Gráfico 3 - Deslocamento para os atrativos turísticos de Ponta Grossa/PR

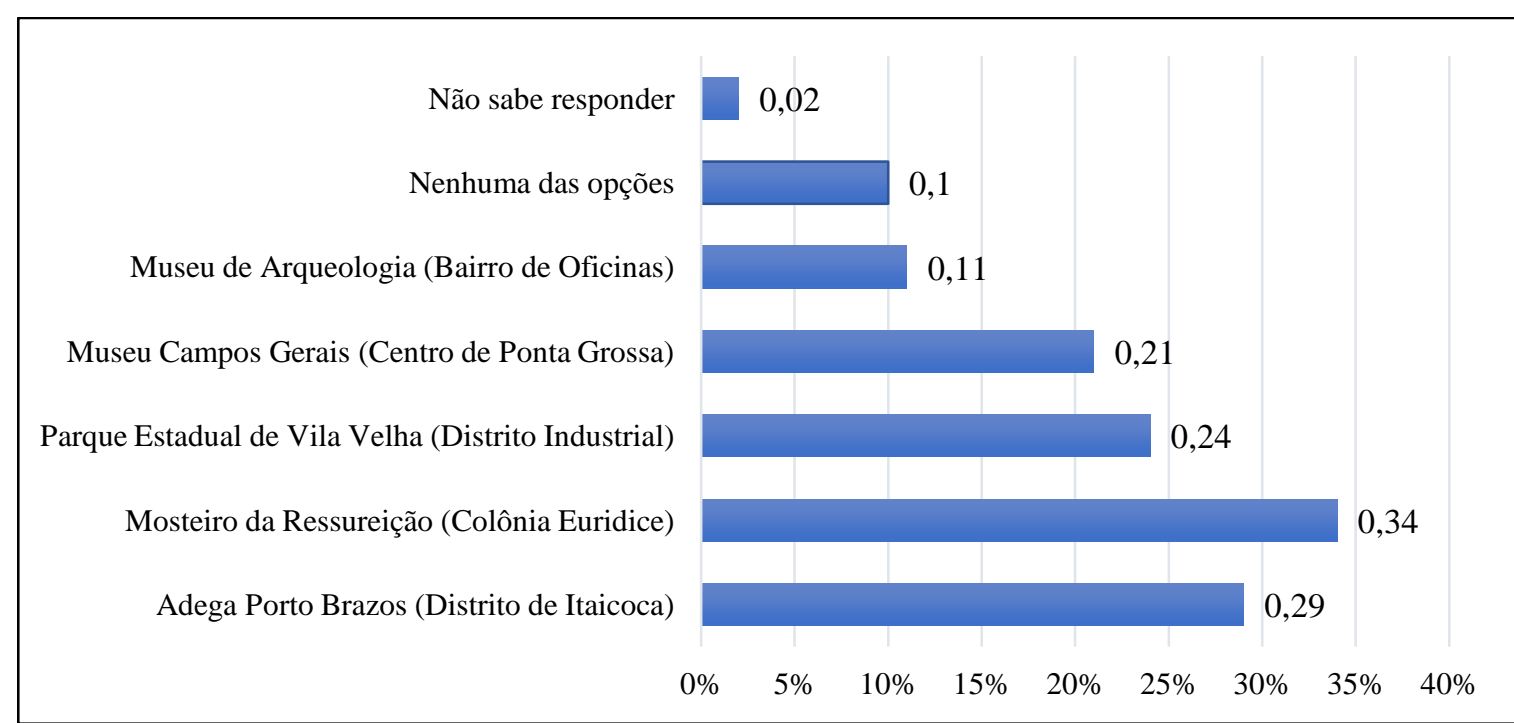

Fonte: Dados obtidos pela autora nas respostas ao questionário aplicado em outubro de 2018.

Mesmo assim, no Gráfico 4, a respeito do cicloturismo em Ponta Grossa, os entrevistados indicam inexistência quanto à infraestrutura cicloviária. Já divulgação dos atrativos, segurança pública, acesso e sinalização, esses itens são classificados como ruins. Por isso, devido aos problemas indicados pelos respondentes, a mobilidade para o cicloturismo em Ponta Grossa é considerada deficiente. Esses itens necessitam não só ser melhorados, mas mais bem planejados, para que esse tipo de turismo tenha algum resultado efetivo para o município, pois, se não existe mobilidade, tido algo essencial para a prática do turismo em si, então não há possibilidade de realizar adequado deslocamento, ficando impossibilitado o cicloturismo. 
Gráfico 4- Qualificação do uso da bicicleta para o turismo em Ponta Grossa

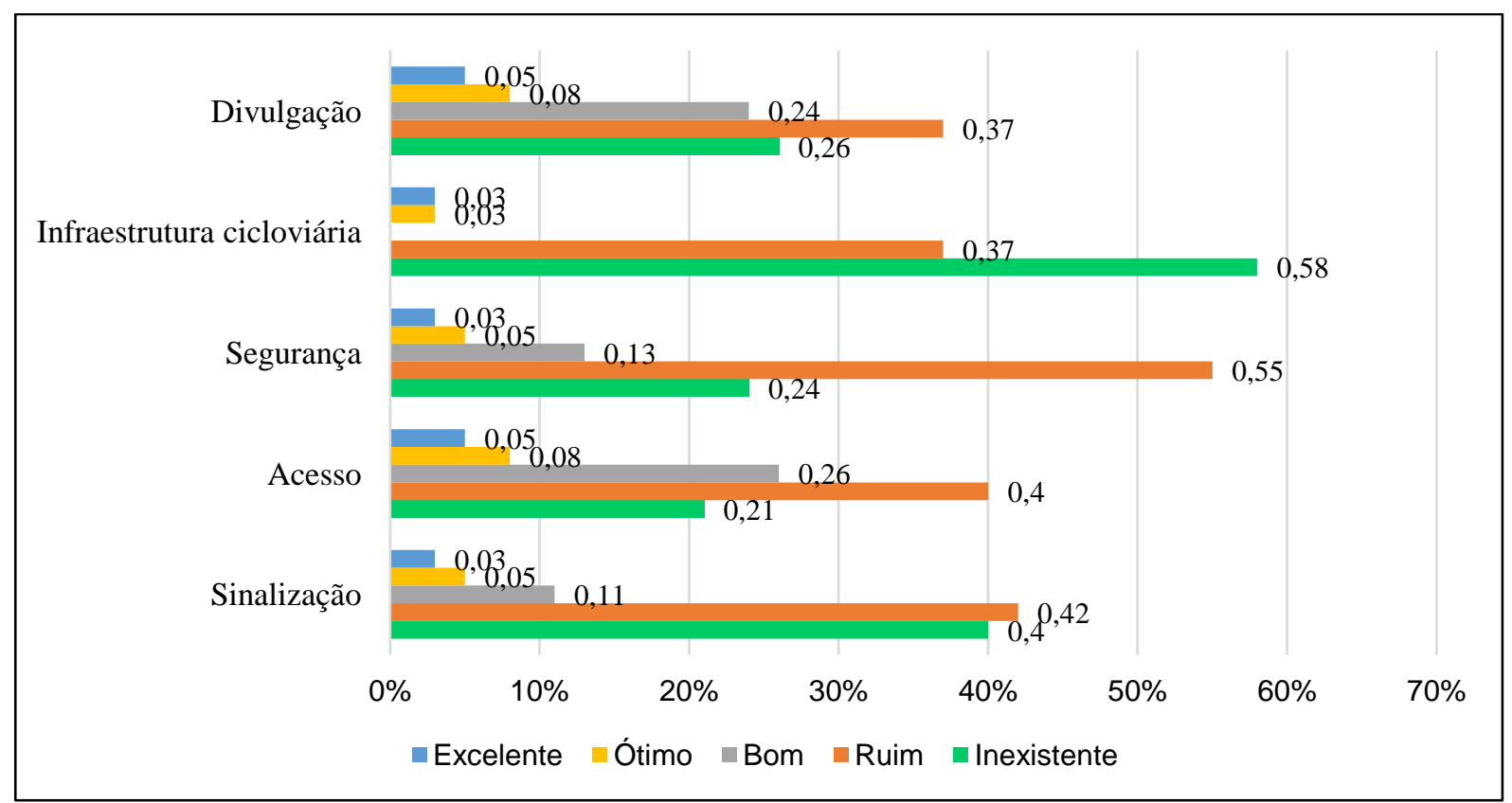

Fonte: Dados obtidos pela autora nas respostas ao questionário aplicado de outubro de 2018

Para tanto, alguns entrevistados expuseram suas opiniões de maneira voluntária, como no Relato A. O/a entrevistado/a menciona que, de fato, não existe incentivo por parte dos próprios ciclistas para que a prática do cicloturismo se torne efetiva. Resta, então, dizer que o interesse não deve partir somente do poder público e da iniciativa privada, mas também do próprio público que pratica essa atividade. A união de todos os agentes deve ser de maneira efetiva, para que a atividade se torne exequível.

Os próprios ciclistas da região não enxergam o cicloturismo como ferramenta de geração de renda. Acham que tudo tem que ser de graça e que ninguém pode prestar um serviço bacana e cobrar. Este tipo de comportamento não incentiva investimento na área. O pessoal vai fazer Vale-Europeu e não reclama de pagar 12 reais num pão de queijo, mas aqui, se fizerem um evento com guias e apoio e pedir 25 reais por um dia todo de pedal, ninguém vai. Então o trabalho mais importante deveria acontecer junto ao empresariado e aos próprios cicloturistas da cidade, no sentido de mostrar o que é feito fora, como é feito e o que pode ser possível ser feito em nossa cidade. Mas acho que este tipo de estudo não existe em lugar algum. (RELATO A).

O Relato B menciona algumas perspectivas de incentivo, mas que ainda são incipientes. Vimos, no capítulo anterior, o projeto que se encontra parado a respeito do cicloturismo e que não obteve continuidade por motivos de gestão. O Plano de Mobilidade de Ponta Grossa conta com algumas iniciativas para a melhoria do ciclismo no município, iniciativas como a implantação de ciclovias, de ciclo-faixas e de sinalização, porém, para que haja 
desenvolvimento do cicloturismo, é necessário que, juntamente com essas obras de infraestrutura, também seja realizada uma forte divulgação dessa atividade em Ponta Grossa.

\begin{abstract}
Algumas iniciativas privadas (ainda que em estágio inicial) já buscam fomentar o cicloturismo na cidade. No entanto, há ineficácia no incentivo ou parceria com o setor público, um dos grandes (se não o maior) responsável pelo incentivo e divulgação do turismo local. Carece de infraestrutura no que diz respeito às condições de pavimentação de acesso aos locais que, em tese, deveriam corresponder a atrativos, tanto os naturais, quanto os histórico-culturais, como o Mosteiro da Ressurreição. Assim como não há sinalização ou segurança pública garantida nesses locais ou no acesso aos mesmos. (RELATO B).
\end{abstract}

O Relato C mostra uma cobrança do ciclista ao poder público, como dito anteriormente, quanto ao projeto para o cicloturismo que se encontra estagnado. Isso leva também a pensar que a implantação da ciclovia em Itaiacoca poderia auxiliar na mobilidade dos próprios moradores do distrito. Reafirma-se, porém, a importância de um planejamento que integre todos os usuários dessa atividade, para que pensem alternativas para que o cicloturismo se desenvolva, até porque não é somente com a implantação da malha cicloviária que o cicloturismo se tornará algo consolidado.

Falta investimentos reais neste setor e não apenas pintar faixas e dizer que criou um espaço adequado para os ciclistas. Falta cumprir a promessa de fazer a ciclovia da UEPG até o Passo de Pupo, pois assim teríamos um cicloturismo de verdade em nossa cidade. (RELATO C).

O Relato D praticamente formula uma crítica ao poder público local, que poderia incentivar para que a atividade se desenvolvesse, com isso criando benefícios não só com relação aos deslocamentos, mas também quanto à saúde de todos os seus usuários, como afirma o comentário do ciclista. Entretanto, as iniciativas previstas não estão sendo executadas como se havia prometido.

Não é de interesse do governo o uso de bicicletas para a locomoção em Ponta Grossa. Um grande exemplo é o simples fato de existir um plano diretor em nossa cidade com uma presente malha cicloviária, porém ninguém está nem aí pra ele. Pensamos assim, quanto mais pessoas utilizando a bicicleta, terá menos carros nos postos de combustíveis, menos pessoas na fila do SUS, menor número de pessoas precisando de remédio do governo, ou seja, o governo não está nem aí pro povo. Por último e não menos importante, será que os comerciantes da cidade acham que ciclista não consome, né, em suas lojas? (RELATO D).

A partir dos resultados obtidos da pesquisa realizada com os os ciclistas de Ponta Grossa, pode-se constatar que a mobilidade turística de Ponta Grossa apresenta muitas deficiências e fragilidades que tornam uma atividade pouco incentivada. Esse incentivo deveria ser oriundo principalmente do poder público, entretanto isso não está acontecendo. Embora existam projetos, parece que eles ainda não tomaram força suficiente para que tornem Ponta Grossa um destino reconhecido. 
Vimos que a união de todos os agentes se torna necessária para que a atividade se desenvolva e com isso possa finalmente trazer benefícios a todos, benefícios esses que poderiam ser em forma de empregos, de opções de lazer, de renda e de outras alternativas de deslocamento, como as ciclovias, por exemplo. Enfim, poderia já estar ativa uma gama de aspectos que outras cidades do Estado do Paraná possuem e que são reconhecidas por isso, mas parece que, infelizmente, o município de Ponta Grossa só conseguirá resultados efetivos talvez a longo prazo.

\section{CONSIDERAÇÕES FINAIS}

Sabe-se que a ideia de colocar em prática atividades sustentáveis para as cidades e para as relações humanas são de extrema importância, principalmente em grandes centros urbanos onde as pessoas procuram por áreas de lazer e práticas de atividades físicas em meio a natureza, fugindo do agito das cidades.

Onde há demanda pelas atividades deve haver uma contrapartida de órgãos públicos e privados para que as atividades aconteçam e tragam benefícios a todos os envolvidos principalmente para aqueles praticantes do cicloturismo. Muitas cidades Paranaenses, e do Brasil por assim dizer, já realizaram resultados satisfatórios em relação a introdução de praticas sustentáves de turismo, lazer e atividades físicas. Com essa pesquisa, pode-se perceber que Ponta Grossa tem a intenção de realizar mudanças e implantar projetos, mas falta um ponta pé inicial para que os projetos sejam alavancados. A união de todos os agentes se torna necessária para que a atividade se desenvolva e com isso possa finalmente trazer benefícios a todos. A partir dos resultados obtidos da pesquisa realizada com os os ciclistas de Ponta Grossa, podese constatar que a mobilidade turística de Ponta Grossa apresenta muitas deficiências e fragilidades que tornam uma atividade pouco incentivada.

As dificuldades dos ciclistas também devem ser destacadas, isso devido à inexistência de ciclovias e ciclo-faixas. Mesmo havendo ciclovias e ciclo-faixas, a existência somente desses aspectos não faz com que haja o desenvolvimento do cicloturismo, pois que essa atividade necessita de outros quesitos, como aspectos ambientais, sociais, culturais e econômicos, para que o cicloturismo se torne efetivo no município de Ponta Grossa.

O cicloturismo constitui-se de uma atividade que depende do uso da bicicleta como principal meio de transporte, para tanto necessita de meios que ofereçam condições para que a atividade em si consiga se concretizar, agentes capazes de fazer a mudança acontecer e uma população que poderá desfrutar do melhor que a cidade pode oferecer no turismo rural. 


\section{AGRADECIMENTOS}

À CAPES- Coordenação de Aperfeiçoamento de Pessoal de Nível Superior.

\section{REFERÊNCIAS}

ALMEIDA, E. P.; GIACOMINI, L. B.; BORTOLUZZI, M. G. Mobilidade e acessibilidade urbana. In: SNCS - Seminário Nacional de Construções Sustentáveis, 2., 2013, Passo Fundo. Anais[...] Passo Fundo: IMED, 2013, p. 1-7. Disponível em: https://www.imed.edu.br/Uploads/Mobilidade\%20e\%20Acessibilidade\%20Urbana.pdf. Acesso em: 12 jan. 2018.

ARRUDA, F. S.de. A Política Nacional de Mobilidade. In: GONZALES, P. W. T.; SOUSA, A. M. de.; SILVA, P. B. (Org.). Acessibilidade e mobilidade urbana na perspectiva da pessoa surda. Goiânia, GO: Kelps, 2017. p. 14-17.

CAMPOS, A.C.; SANTOS, C. A.de.J. ; ALVES, 1. A.de C. Cicloturismo: mobilidade urbana e valorização do turismo da cidade de Aracaju - Sergipe. Revista de Direito da Cidade, v. 08, n.4. pp. $1800 \quad-\quad 1824$. Disponível em: https://www.epublicacoes.uerj.br/index.php/rdc/article/view/22642/19160. Acesso em: 18 dez 2019.

CARLOS, A. F. O consumo do espaço. In: CARLOS, A. F (org). Novos caminhos da geografia. 5.ed. São Paulo: Contexto, 2005.p.173-186.

DUARTE, F. Planejamento urbano. Curitiba: Ibpex, 2013.

GASTAL, S.; MOESCH, M. Turismo, políticas públicas e cidadania. São Paulo: Aleph, 2007.

GRIMM, I. J.; RODRIGUES, A. A. mobilidade urbana e o cicloturismo: para (re)pensar o planejamento das cidades. 7.,2018, São Paulo. Anais [...] São Paulo: SINGEP, 2018. Disponível em: https://singep.org.br/7singep/resultado/30.pdf. Acesso em: $18 \mathrm{dez} 2019$. 
PREFEITURA MUNICIPAL DE PONTA GROSSA. Prefeitura avança em projeto de ciclovia que liga Uvaranas a Itaiacoca. Imprensa Prefeitura de Ponta Grossa, Ponta Grossa, 27 nov. 2017b. Disponível em: http://www.pontagrossa.pr.gov.br/node/37617. Acesso em: 1 jan. 2018.

RELATO A. Mobilidade turística. [out.2018]. Ponta Grossa: Ciclistas, 2018. Questionário estruturado. Entrevista concedida disponibilizada em ambiente virtual no período de 20 a 29 de outubro de 2017.

RELATO B. Mobilidade turística. [out.2018]. Ponta Grossa: Ciclistas, 2018. Questionário estruturado. Entrevista concedida disponibilizada em ambiente virtual no período de 20 a 29 de outubro de 2017.

RELATO C. Mobilidade turística. [out.2018]. Ponta Grossa: Ciclistas, 2018. Questionário estruturado. Entrevista concedida disponibilizada em ambiente virtual no período de 20 a 29 de outubro de 2017.

RELATO D. Mobilidade turística. [out.2018]. Ponta Grossa: Ciclistas, 2018. Questionário estruturado. Entrevista concedida disponibilizada em ambiente virtual no período de 20 a 29 de outubro de 2017.

SALDANHA, L.; PEIXOTO, M.; FRAGA, C. O Papel de instrumentos de planejamento para o desenvolvimento do cicloturismo em âmbito internacional. XIII Rio de Transportes, 2015.

SANTOS, M. Espaço e Método. 4.ed. São Paulo: Nobel, 1997.

TRANSPORTE ATIVO. Parceria nacional pela mobilidade por bicicleta: pesquisa nacional sobre o perfil do ciclista brasileiro, 2018. Disponível em:< http://ta.org.br/perfil/ciclista18. pdf>.Acesso em: 15 out 2018. 